\title{
Construção colahorativa do conhecimento com objetos de aprendizagem em um ambiente virtual de aprendizagem
}


Resumo. É apresentado um Ambiente Virtual de Aprendizagem (AVA), chamado Hospital Educacional, que aplica recursos de Inteligência Artificial e ludicidade para apoiar o professor e estimular os alunos na construção e difusão do conhecimento, de maneira colaborativa, através de Objetos de Aprendizagem Reutilizáveis. O Hospital Educacional, além de ser um AVA, é um repositório de Objetos de Aprendizagem criados pelos alunos, onde estes objetos são compartilhados livremente para escrever textos (artigos) e para preparação de aulas pelos usuários do ambiente.

Palavras-chave: Ambiente Virtual de Aprendizagem (AVA). Inteligência Artificial (IA). Informática na Educação. Objetos de Aprendizagem Reutilizáveis.

Abstract. This paper describes a Virtual Learning Environment (VLE), called Hospital Educacional, which applies Artificial Intelligence and ludicity techniques in order to support the professor and motivate the students in order to build and disseminate knowledge in a collaborative way using Reusable Learning Objects. Besides being a VLE, the Hospital Educacional is also a Learning Objects repository created by the students, where these objects are freely shared among the users in order to write papers and prepare classes.

Keywords: Virtual Learning Environment (VLE). Artificial Intelligence (IA). Computing in Education. Reusable Learning Objects.

CARDOSO, Antônio Luiz Mattos de Souza; BURNHAM, Teresina Fróes . Construção colaborativa do conhecimento com objetos de aprendizagem em um ambiente virtual de aprendizagem. Informática na Educação: teoria \& prática, Porto Alegre, v.10, n.1, p.75-86, jan./jun. 2007. 


\section{Introdução}

O simples uso de tecnologia não garante a melhoria do processo de ensino-aprendizagem. Seria uma impropriedade admitir que o computador em si em um ambiente de Educação a Distância, através de seus recursos e pela forma como disponibiliza os materiais instrucionais para o estudante seja garantia de aprendizagem [Moreira et al. 2006].

EaD supõe relação, interação e conectividade. Isso porque ensinar não é simplesmente repassar informações, além do que o aluno não é apenas um mero receptáculo de idéias; para que a aprendizagem ocorra, é preciso uma adaptação e uma reconstrução das informações recebidas. A comparação e a articulação dos novos conhecimentos com aqueles já consolidados exigem um diálogo constante entre o professor e os alunos, assim como também entre os alunos. Freqüentemente, este segundo aspecto é esquecido ou mesmo negligenciado.

Apesar de no contexto da EAD o aluno não contar, comumente, com a presença física do orientador, mesmo assim ela exige relação dialógica efetiva. A EAD impõe uma organização que possibilite uma interlocução permanente entre os sujeitos da ação pedagógica. Dentre estes elementos, estão à criação de ambientes virtuais (e reais) que favoreçam o processo de estudo dos alunos e o processo de orientação acadêmica.

Os novos recursos tecnológicos podem, dependendo da forma como seja planejada a sua utilização, enriquecer e ampliar as condições e as chances de aquisição e construção do conhecimento do aluno ao adotar diferentes abordagens, complementares aos 'tradicionais' recursos.

Os recursos tecnológicos podem também possibilitar a descentralização do trabalho pedagógico. Não cabe apenas ao professor transmitir conhecimentos e ao aluno absorvê-los de maneira passiva. A realização cooperativa de atividades de aprendizagem é importante no processo de aprendizagem. Viabilizar e facilitar a participação e o intercâmbio entre alunos, para debater opiniões e idéias sobre os temas estudados, amplia de modo significativo as chances de crescimento do aluno.

Portanto, o professor não é apenas o organizador do processo de aprendizagem, ele é principalmente o mediador das ações dos alunos. Como Lévy (1999) escreve “...o professoré incentivado a torna-se um animador da inteligência coletiva de seus grupos de alunos em vez de um fornecedor direto de conhecimentos". Então, o professor deve provocar e propiciar as atividades do aluno; permitindo ao aluno realizar a ação de análise e reflexão crítica. Do outro lado, os alunos devem ser estimulados a produzir conhecimento, colaborar com outros colegas e gerenciar seu próprio processo de aprendizagem [Palloff e Pratt 2002].

Este trabalho apresenta um Ambiente Virtual de Aprendizagem (AVA), o Hospital Educacional(http://www.hospitaleducacional. com), que é utilizado em uma sala de aula presencial para potencializar e compreender as relações de ensino-aprendizagem que existem entre professores e alunos e entre os próprios alunos, mas que muitas vezes passam despercebidas ou mesmo ignoradas.

O Hospital Educacional congrega professores e alunos com a intenção de ampliar as condições de ensino e aprendizagem pela mediação das Tecnologias de Informação e Comunicação, sendo baseado em uma proposta de aprendizado colaborativo.

O aprendizado colaborativo é uma situação na qual os alunos se reúnem em grupo em 
busca de conhecimento, respeitando as habilidades individuais e suas contribuições. Existe um compartilhamento de responsabilidades entre os membros do grupo para a realização das ações. A premissa desse aprendizado é baseada num consenso de construção do conhecimento através da cooperação entre os membros do grupo e não da competição [Panitz 1996].

Em [Komosinski 2000], é apresentada uma lista de benefícios do aprendizado colaborativo:

- Desenvolve habilidades de pensamento crítico de mais alto nível através da discussão;

- Promove a interação e familiaridade entre aluno e professor;

- Incrementa a satisfação do estudante com a experiência de aprendizagem e, conseqüentemente, a retenção de conteúdos;

- Desenvolve habilidades de comunicação oral e social; e

- Estimula a formação de equipe e uma abordagem baseada em equipe para a solução de problemas enquanto mantém a responsabilidade individual.

A Aprendizagem Colaborativa é uma estratégia de ensino que encoraja a participação do estudante no processo de aprendizagem e que faz da aprendizagem um processo ativo e efetivo [Torres 2004].

A simples construção e disponibilização deste ambiente não indica o caminho do sucesso em uma perspectiva educacional [Moreira et al. 2006]. O Hospital Educacional não prescinde do professor e, muito menos, da sala de aula. Ele está sendo elaborado na perspectiva de ser utilizado pelo professor em sala de aula apresentando o material de estudo aos alunos e, após a aula, para ser utilizado pelo professor e alunos para a troca de informações, leitura de material didático e construção do conhecimento.

\section{O Ambiente}

No Hospital Educacional, foram implementadas técnicas de Recuperação da Informação e Inteligência Artificial, baseadas em Processamento de Linguagem Natural, que possibilitaram construir uma solução de software que simula um tutor humano, de maneira que a solução responde automaticamente a consultas (perguntas) formuladas pelos alunos em linguagem natural (na língua portuguesa).

O Hospital Educacional ainda está em processo de construção, com algumas funcionalidades implementadas, onde os alunos já têm a sua disposição:

- Acesso ao material de estudo apresentado em sala de aula;

- Acesso a material de estudo adicional e complementar, tais como, artigos e treinamentos pré-existentes na $W e b$;

- Um espaço para trocar experiências online que permite a interatividade entre aluno-aluno;

- Um espaço para obter orientações sobre o material de estudo a partir de dúvidas e questionamentos formuladas através de consultas;

- Um repositório de Objetos de Aprendizagem constituído por fatos, resumos e conceitos, oriundos das orientações propostas pelos alunos, que podem ser (re)utilizados na confecção de textos (artigos) e preparação de aulas (apresenta- 
ções e planos de aula).

De outra perspectiva, os professores possuem a sua disposição:

- Um repositório para publicar material de estudo para difusão aos alunos;

- Um espaço para trocar experiências onlineque permite a interatividade professoraluno;

- Uma ferramenta para captar dúvidas e questionamentos dos alunos através da formulação de consultas; e

- Uma ferramenta para propor orientações automáticas às consultas diminuindo esforço e tempo nesta atividade.

O Hospital Educacional processa as consultas submetidas pelos alunos que desejam sanar dúvidas sobre assuntos abordados pelo professor em uma sala de aula presencial ou sobre assuntos contidos no material de estudo disponibilizado no próprio Hospital Educacional. As orientações são respostas às consultas encaminhadas pela solução automaticamentesem interferência humana.

Caso não haja uma orientação automática a uma consulta, ela é aberta à comunidade para que voluntários possam respondê-la, em um contexto colaborativo. Nesta primeira fase, as orientações propostas pelos alunos são mediadas pelo professor ou tutor antes que seja encaminhada a quem pergunta. Em futuro próximo, espera-se que as orientações não sejam mais mediadas pelo professor nem pelo tutor,mas que a própria comunidade de alunos se encarregue da mediação, caso seja necessária.

No Hospital Educacional, foi incluído um dicionário de sinônimos da língua portuguesa com aproximadamente 38.000 entradas e
500.000 sinônimos, 220 regras gramaticais e outros recursos lingüísticos para processamento de linguagem natural' ${ }^{1}$.

Assim, o Hospital Educacional, no uso de seus recursos de Recuperação da Informação e Inteligência Artificial, percebe variações gramaticais e morfológicas dos termos das consultas submetidas pelos alunos de maneira a entendêlas e assim buscar, na sua Base de Conhecimentos, a informação mais precisa e adequada, respondendo automaticamente aos questionamentos.

Ou seja, não há uma comparação simples e textual das consultas formuladas pelos colaboradores com as perguntas previamente registradas no Hospital Educacional, mas há um processamento inteligente que capta a necessidade do aluno encaminhando uma orientação sem intervenção humana.

O ambiente possui também uma interface lúdica em que simula um Hospital real, onde os usuários assumem diferentes papéis no ambiente.

Deve-se compreender a interface do Hospital Educacional como um jogo lúdico, onde as suas diversas funcionalidades simulam um Hospital real em um paralelismo virtual. A intenção é utilizar a riqueza do ambiente gráfico da Internet com mensagens de impacto, não necessariamente acadêmicas. Esta é a leitura que deve ser feita da Interface do ambiente.

Entre os vários paralelos contidos no ambiente, temos, por exemplo, o material de estudo que está contido no Receituário, o ProntoSocorro que é o local para postar consultas e a Farmácia onde se obtém remédios para as consultas. As Clínicas Médicas são acessos (links na Internet) para treinamentos e outros materiais externos ao Hospital Educacional. 
Os alunos que propõem as orientações (remédios) são Doutores eos Enfermeiros são aqueles que validam as orientações, antes que elas sejam efetivadas na Base de Conhecimentos.

Além deste paralelismo, imagens animadas foram especialmente construídas para transmitir mensagens lúdicas direcionadas para a educação no trânsito e também contra as drogas; dois aspectos que assolam a juventude brasileira, que são os usuários preferenciais do Hospital Educacional. Algumas dessas imagens são apresentadas aqui:

Figura 1. Imagens da ambiente do Hospital Educacional

o Ministério da Educação adverte: Estudar faz bem a Saúde.

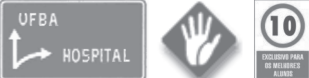

Assim, o Hospital Educacional possui duas características que o distingue bem de outros Ambientes Virtuais de Aprendizagem: (1) temática e interface lúdicas e (2) sistema de Perguntas e Respostas inteligente.

A intenção é potencializar a participação dos alunos em um ambiente efetivamente de aprendizagem com uma interface mais criativa e estimulante, fugindo daquilo que foi alertado por Santos (2002):

Portanto, cabe-nos questionar: será que estamos diante de uma revolução nas formas de ensinar e aprender ou o que está sendo disponibilizado, via AVA, são meras repetições instrucionais? Nos últimos dois anos, venho pesquisando e analisando AVA no ciberespaço e, a cada dia, a cada nova experiência, tenho me indignado muito. Venho observando que muitas experiências instrucionistas em elearning acabam sendo legitimadas até por associações de pesquisas científicas...

Neste processo de consulta-orientação, os alunos não apenas buscam conhecimentos para si, através da formulação de consultas, mas também contribuem ao propor orientações efetivas para as consultas de seus pares, em um processo de construção colaborativa do conhecimento em que todos os participantes ganham (espírito de comunidade). Ganham demandando informações e, também, propondo orientações.

$E$, mais ainda, não apenas o conhecimento explícito, contido nos livros didáticos ou apresentado em sala de aula, é empregado nas orientações às consultas, mas o conhecimento implícito, conhecido apenas individualmente, é devidamente registrado, colocado à disposição de todos os alunos usuários atuais e, importante, acessado pelos futuros.

\section{O Processo de Trabalho}

Daí emerge a primeira justificativa deste projeto: a perspectiva de registrar o conhecimento concebido pelos alunos em um determinado momento e construi-lo para os alunos das turmas seguintes, para aqueles que ainda estão por vir. Pois, é freqüente a realidade de que o conhecimento trabalhado em uma sala de aula num determinado período escolar deva ser novamente (re)construído para os alunos das turmas vindouras, como que perdido ou mesmo ignorado o que foi realizado. Freqüentemente, os alunos das novas turmas desconhecem o que foi trabalhado nas turmas anteriores e, por outro lado, os professores muitas vezes não têm instrumentos eficientes para resgatar o passado.

Além de construir o conhecimento para frente, o ambiente possibilita aos alunos futuros uma outra perspectiva: adicionar ao conhecimento, registrado na Base de Conhecimentos, novas informações, complementando, alterando ou mesmo corrigindo-o. Esta perspectiva nos

remete a um conceito fundamental deste projeto: a produção hipertextual colaborativa, 
definida por Johnson-Eilola como "escrita colaborativa". Johnson-Eilola [apud Marcuschi 2001] frisa que esse conhecimento

...não existe como uma verdade preconcebida esperando impacientemente para ser descoberta, mas antes como uma verdade potencial... Até que a criemos, nos liguemos a ela, a escrevamos ou a recubramos - "ela" não existe; a Verdade é nossa verdade. Nós criamos esse conhecimento contextualmente e o partilhamos eletronicamente não pelo convencimento de alguém de que estamos certos, mas seguindo sua exploração por nossas conexões e explorando sua ordem para negociar nossos espaços partilhados...

Estas duas perspectivas podem ser claramente observadas em outros trabalhos colaborativos na Web como, por exemplo, na Wikipédia, "uma enciclopédia escrita em colaboração pelos seus leitores", baseada na ferramenta Wiki (http://wikipedia.org/).

Mesmo não sendo mensurada quantitativamente, percebe-se a motivação dos alunos na utilização e nas proposições ao Hospital Educacional. Ela é percebida não apenas na participação ativa dos alunos na proposição de orientações aos seus pares, mas também em sugestões de novos conteúdos e melhorias funcionais ao ambiente.

Ou seja, o interesse dos alunos não é apenas em receber informações, mas também contribuir ativamente na construção e difusão do conhecimento. Isto sugere ou indica o surgimento de uma Comunidade Virtual de Aprendizagem, em uma perspectiva muito mais ampla que simplesmente um Ambiente Virtual de Aprendizagem.

Outro aspecto que reforça a idéia de uma Comunidade Virtual de Aprendizagem é que as orientações são propostas não necessariamente por quem já sabe aresposta, mas por aqueles que pesquisam e estudam sobre o tema da consulta para propô-la. Isto reflete uma das principais características das Comunidades de Aprendizagem: a autonomia e a capacidade de autoaprendizagem [Afonso 2001].

O Hospital Educacional proporciona aos alunos um ambiente colaborativo de ensino e aprendizagem estabelecendo uma interação aberta aluno-aluno e não simplesmente uma interação única e impositiva professor-aluno, como freqüentemente ocorre em uma sala de aula. Através dessa interação, os alunos podem estabelecer relações de ensino e aprendizagem entre si.

Cada orientação proposta e aceita para as consultas abertas é registrada em um repositório indexado o qual permite a sua recuperação. A recuperação ocorre pelas palavraschave contidas nas consultas.

Os termos das consultas (palavras-chave) tornam-se, assim, os metadados neste repositório. Através deste mecanismo de armazenagem e recuperação, tornou-se possível avançar em mais uma proposta de construção e difusão do conhecimento e aprendizagem: um Repositório de Objetos de Aprendizagem.

As orientações são objetos que podem ser (re)utilizados pelos professores e alunos, além de qualquer visitante (usuário) do Hospital Educacional, mediando uma outra prática pedagógica. Há diferentes conceitos sobre Objetos de Aprendizagem. Por exemplo, Wiley (2000) os define como qualquer recurso digital que pode ser reutilizado para apoiar à aprendizagem. Outra definição, proposta em Muzio et. al. (2001), indica que objeto de aprendizagem é um pedaço de informação granular e reutilizável independente de mídia para propósitos instrucionais.

O ambiente permite recuperar as orien- 
tações (pedaços de informação) para serem reutilizados em diferentes perspectivas: (1) na composição de textos (artigos) e (2) na preparação de aulas (apresentações e planos de aula). Estas perspectivas ou estratégias pedagógicas de manipulação dos Objetos de Aprendizagem não são as únicas possíveis, mas são aquelas que estão sendo efetivamente realizadas pelos alunos no Hospital Educacional.

A estratégia pedagógica dependerá principalmente dos objetivos de aprendizagem do professor ou do interesse de quem busca um objeto no repositório. A (re)utilização de objetos é interessante, pois propicia a manipulação ( hands-on) do conhecimento, não permitindo que ele fique apenas armazenado como que morto e enterrado, mas tornando-o vivo e disponível.

Wagner (2002) propôs um modelo que representa a construção de recursos de aprendizagem a partir de pequenos objetos reutilizáveis. Seu modelo foi adaptado para a proposta do Hospital Educacional, conforme apresentado na Figura 2.

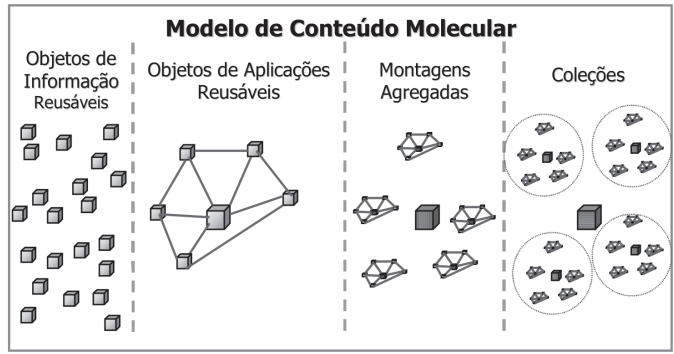

Figura 2. Modelo de Conteúdo Molecular adaptado

Lendo o modelo acima, os Objetos de Informação Reusáveis são as orientações armazenadas na Base de Conhecimentos. Os Objetos de Aplicações Reusáveis são artigos e aulas criados a partir da combinação dos Objetos de Informação. A intenção futura, a partir da combinação dos Objetos de Aplicação, é criar cursos ou livros/apostilas sobre Sistemas de Informação. Toda esta Coleção forma o Hospital Educacional, em outras palavras, um Ambiente Virtual de Aprendizagem.

Este Ambiente Virtual de Aprendizagem proporciona três objetivos didáticos bem definidos em um crescente pedagógico:

1. Um espaço para os alunos exprimirem suas dúvidas sobre o material de estudo;

2. Um espaço para os alunos dirimirem dúvidas de seus colegas, em uma relação entre iguais;

3. Um espaço para manipular, construir e difundir novos conhecimentos.

\section{Resultados Obtidos}

O Hospital Educacional foi iniciado no segundo semestre de 2005 no Centro Federal de Educação Tecnológica da Bahia (CEFET-BA) com poucas funcionalidades ativas em um programa executado no ambiente MS-Windows XP.

Desde 2006-1, está sendo aplicado na Escola de Administração da UFBA (EAUFBA). Inicialmente, de maneira limitada, como uma solução Cliente-Servidor (TCP/IP). Atualmente, com uma interface paraa Web. Mesmo ainda em processo de desenvolvimento, o projeto apresenta alguns resultados que merecem destaque:

-338 alunos participantes, sendo $25 \mathrm{em}$ 2005-2, 78 (2006-1), 97 (2006-2), 73 (2007-1) e 65 (2007-2);

- 6.303 consultas formuladas pelos alunos, sendo 436 em 2005-2, 2.187 (2006-1), 1.436 (2006-2), 1.738 (2007-1) e 506 (2007-2);

- 2.973 orientações propostas pelos alunos às consultas, sendo que $79,04 \%$ aceitas pelo professor; 
- 1.768 orientações propostas automaticamente pela solução, sendo 365 em 2006-1, 531 (2006-2), 661 (2007-1) e 211 (2007-2); e

- 05 artigos elaborados e 04 aulas preparadas, com acesso livre ao público, segundo os termos e condições do Open Publication License $^{2}$

Contabiliza-se também o aumento da capacidade da solução em propor orientações de maneira automática às consultas. Em 20052 , nenhuma consulta teve orientação encaminhada automaticamente pelo ambiente, pois não havia interação direta com os alunos. Em $2006-1,16,70 \%$ das consultas tiveram orientações propostas automaticamente. Em 2006-2,

$36,95 \%$ das consultas tiveram orientações automáticas. Em 2007-1, 38.05\%. Em 2007-2 (até outubro), este índice encontra-se em $41,69 \%$.

Cada nova orientação, proposta por um aluno, é um novo insumo que alimenta a Base de Conhecimentos. Assim, espera-se que a capacidade de propor orientações automaticamente aumente naturalmente à medida que a Base de Conhecimentos cresça, com a adição de orientações.

Esta capacidade crescente em responder automaticamente as consultas dos alunos, ou seja, a 'sua inteligência' pode ser melhor observada graficamente conforme a Figura 3.

A Figura 4 enumera a totalidade de orientações armazenadas (4.174) na Base de Conhecimentos, classificadas por temas. As orientações contemplam 02 disciplinas de Tecnologia da Informação e Conhecimento (Sistemas de Informação Gerencial e Administração de Sistemas de Informação) com 06 temas (Redes de Computadores, Segurança Digital, Banco de

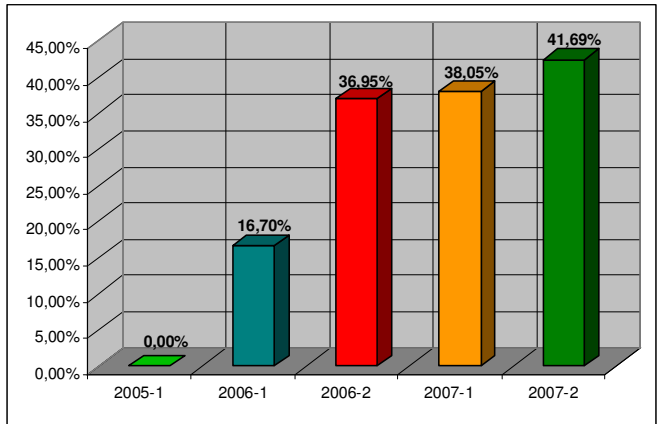

Figura 3. Índice de orientações automáticas

Dados, Engenharia de software, Sistemas Operacionais e Sistemas de Informação).

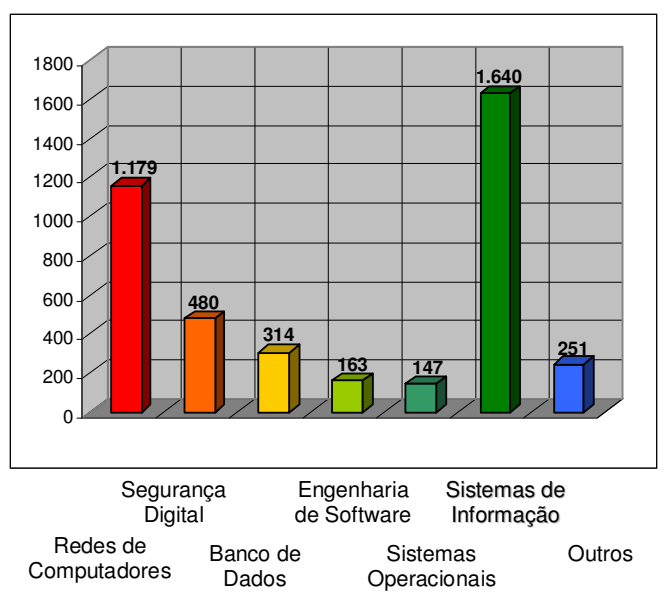

Figura 4. Classificação das consultas pelo Tema na Base de Conhecimentos

A Tabela 1 apresenta os dados sobre as orientações propostas pelos alunos e quantas delas foram consideradas corretas e aceitas pelo professor, classificadas por semestre.

Para estimular a participação dos alunos, alguns instrumentos pedagógicos estão

\begin{tabular}{|c|c|c|c|c|}
\hline $\begin{array}{c}\text { Período } \\
\text { Letivo }\end{array}$ & $\begin{array}{c}\text { Número } \\
\text { de Alunos }\end{array}$ & $\begin{array}{c}\text { Orientações } \\
\text { Propostas }\end{array}$ & $\begin{array}{c}\text { Orientações } \\
\text { Aceitas }\end{array}$ & $\begin{array}{c}\text { Orientações } \\
\text { Aceitas (\%) }\end{array}$ \\
\hline $2006-2$ & 50 & 721 & 531 & $73.65 \%$ \\
\hline $2007-1$ & 87 & 1.951 & 1.558 & $79.86 \%$ \\
\hline $2007-2$ & 29 & 301 & 261 & $86.71 \%$ \\
\hline
\end{tabular}

Tabela 1. Orientações propostas por semestre 
sendo utilizados:

- Pontuação para os alunos que submetem consultas e propõem orientações;

- Concessão de Certificado de Participação em Pesquisa Científica;

- Concessão de Certificado de Monitoria;

- Concessão de Bolsa de Iniciação Científica, a depender de aprovação de instituições de fomento à pesquisa ${ }^{3}$.

As orientações propostas pelos alunos para seus pares potencializam o relacionamento aluno-aluno e explicitam um conhecimento que normalmente está oculto ou restrito a poucos na sala de aula.

Com o amadurecimento deste trabalho, a validação das orientações será realizada pelos próprios alunos nos próximos semestres, de maneira a corrigir, melhorar ou ajustá-las dispensando a validação obrigatória pelo professor (gestor), conforme ocorre em outras propostas de trabalho colaborativo na Web, por exemplo, na Wikipédia (http://wikipedia.org/).

\section{Futuros Desenvolvimentos e Considerações Finais}

A combinação de diferentes técnicas de Processamento de Linguagem Natural e Recuperação da Informação possibilitou o desenvolvimento de uma solução de software que compara consultas formuladas em linguagem natural identificando aquelas que são similares. Havendo uma orientação armazenada na Base de Conhecimentos da solução, as consultas similares são respondidas automaticamente sem interferência humana.

Conforme apresentado anteriormente, o índice de respostas automáticas está em
41.74\%. Ou seja, para cada cem consultas, 41 são respondidas sem interferência humana.

À medida que a Base de Conhecimentos cresce, a probabilidade do ambiente responder de modo automático a consultas aumenta potencialmente. Isto porque as novas consultas poderão ter fortes tendências de similaridade por serem baseadas em um conteúdo didático similar.

Uma das mais importantes funcionalidades, que está em processo de desenvolvimento no Hospital Educacional, é a adição de voz humana ao ambiente. Nesta nova funcionalidade, as orientações serão dadas aos alunos em voz humana, na língua portuguesa, através de Avatares. Acredita-se que esta funcionalidade será extremamente estimulante para os alunos, estimulando a participação deles neste projeto.

Quanto à participação dos alunos, podese dizer que é notória não apenas pelos dados apresentados. Em conversas informais com os alunos, muitos relatam a sua experiência na utilização do ambiente como "muito proveitosa...". Outros estabeleceram a URL do Hospital Educacional na Internet como sua página de acesso à Internet.

Como a solução foi desenvolvida em módulos e cada ferramenta de IA foi implementada separadamente e integrada posteriormente, tornou-a muito versátil de modo que ela pode ser integrada facilmente a outros ambientes de EaD.

O Hospital Educacional ainda está em desenvolvimento para que se torne uma 'Sala de Aula Virtual' para outras áreas do conhecimento humano. Atualmente, o Hospital Educacional processa apenas consultas sobre Informática, porém não há nenhuma restrição técnica para processar diferentes áreas do conhecimento humano. À medida que parcerias sejam feitas com professores de outras áreas ou mesmo ins- 
tituições de ensino, elas poderão ser adicionadas à Base de Conhecimentos do Hospital Educacional.

Quando este ambiente educacional estiver devidamente construído, amparado por pre- ceitos educacionais consistentes, poderá contribuir fortemente para o crescimento intelectual dos alunos que estejam envolvidos com ele, além de apoiar os professores na difusão do conhecimento existente em sala de aula.

\section{Referências}

Afonso, A. P. (2001), "Comunidades de Aprendizagem: um Modelo para a Gestão da Aprendizagem”. In: Procedure of the II Conferência Internacional de Tecnologias de Informação e Comunicação na Educação, pp. 427-432, Challenges 2001 / Desafios 2001, Braga, Portugal.

Komosinski, L. J. (2000), "Um Novo Significado para a Educação Tecnológica fundamentada na Informática como Artefato Mediador da Aprendizagem". 146f. Tese de Doutorado (Engenharia de Produção) - Programa de Pós-Graduação em Engenharia de Produção - Universidade Federal de Santa Catarina, Florianópolis.

Levine, R. I. et al. (1988), "Inteligência Artificial e Sistemas Especialistas - Aplicações e Exemplos Práticos". 1 ${ }^{a}$ ed. São Paulo: McGRAW-HILL.

Lévy, P. (1999), "CIBERCULTURA”. 1aㅡ ed. São Paulo: Editora 34.

Marcuschi, L. A. (2001), "O Hipertexto como um Novo Espaço de Escrita em Sala de Aula". Revista Linguagem \& Ensino, Vol. 4, No. 1, (79-111). Revista do Curso de Mestrado em Letras, Universidade Católica de Pelotas.

Moreira, M. et al. (2006), "A EaD no Processo de Democratização do Ensino Superior no Brasil", In: Desafios da Educação a Distância na Formação de Professores. Brasília: Secretaria de Educação a Distância - Ministério da Educação, cap. 13, p. 191-210.

Muzio, J. et. al. (2001), "Experiences with Reusable eLearning Objects: From Theory to Practice". Royal Roads University, Victoria, Canadá. Disponível em: <http://www.udutu.com/pdfs/eLearningobjects.pdf>>. Acesso em: 11 jul. 2007.

Palloff, M. e Pratt, K. (2002), "Construindo Comunidades de Aprendizagem no Ciberespaço". 1aㅡ. ed. Porto Alegre: Artmed.

Panitz, T. (1996), "A Definition of Collaborative vs. Cooperative Learning". Disponível em: <http:// www.londonmet.ac.uk/deliberations/collaborative-learning/panitz-paper.cfm>. Acesso em: 11 jul. 2007.

Santos, E. (2002), “Ambientes Virtuais de Aprendizagem: por Autorias Livres, Plurais e Gratuitas”. Revista FAEEBA - Educação e Contemporaneidade, Salvador, v. 11, n. 18, p. 425-435, jul./dez. 2002.

Torres, P. et al. (2004), "Grupos de Consenso: Uma Proposta de Aprendizagem Colaborativa para o Processo de Ensino-Aprendizagem". Revista Diálogo Educacional, Curitiba, v.4, n.13, p.129-145, set./ dez. 2004.

Wiley, D. A. (2000), "Connecting Learning Objects to Instructional Theory: A Definition, a Methaphor, and a Taxonomy". The Instructional Use of Learning Objects - Online Version. Open Publication License. Disponível em: <http://www.reusability.org/read/>. Acesso em: 11 jul. 2007. 
teoria \& prática Porto Alegre, v.10, n.1, jan./jun. 2007. ISSN 1516-084X

\author{
Recebido em março de 2007
}

Aceito para publicação em julho de 2007

\title{
Notas
}

${ }^{1}$ A inteligência dos computadores depende das pessoas que os fazem; como eles não conseguem "pensar" por si, temos de lhes dar instruções muito específicas para cada função a ser executada... Para fazer um computador entender uma língua, não apenas temos de dividir essa língua em seus elementos básicos e inserir esses dados no computador como temos também de desenhar computadores e programas de computadores que em primeiro lugar aceitem essas informações [LEVINE et al. 1988, p. 25].

2 Open Publication License (última versão disponível em http://opencontent.org/openpub/).

${ }^{3}$ Uma Bolsa de Iniciação Científica PIBIC foi aprovada pela FAPESB (Fundação de Amparo à Pesquisa do Estado da Bahia) por um período de 01 ano iniciada em 2007-2.

Antônio Luiz Mattos de Souza Cardoso

Doutorando PPGE, Faculdade de Educação, UFBA, Salvador, BA, Brasil.

Teresina Fróes Burnham

Doutora PPGE, Faculdade de Educação, UFBA, Salvador, BA, Brasil. 